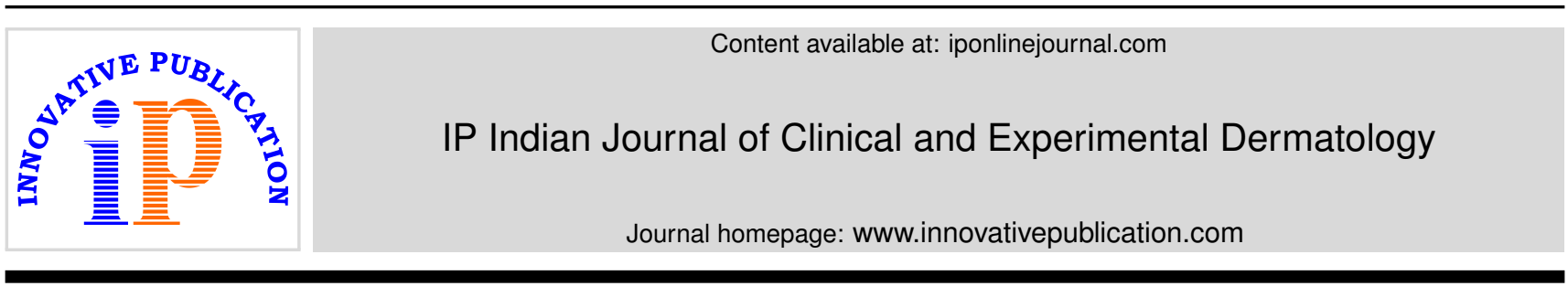

Original Research Article

\title{
A study of geriatric dermatoses in a rural based tertiary care hospital in South India
}

\author{
Raghavendra B N ${ }^{\mathbf{1}}$, Rajesh $\mathbf{G}^{\mathbf{2}, *}$ \\ ${ }^{1}$ Dept. of Dermatology, MVJ Medical College and Research Hospital, Bengaluru, Karnataka, India \\ ${ }^{2}$ Dept. of Dermatology, Akash Institute of Medical Sciences and Research Centre, Bengaluru, Karnataka, India
}

\section{A R T I CLE I N F O}

Article history:

Received 10-02-2020

Accepted 11-03-2020

Available online 21-04-2020

Keywords:

Eczematous dermatitis

Geriatric population

Pruritus

Skin disease

\begin{abstract}
A B S T R A C T
Introduction: Dermatological problems in the geriatric population are common and often underestimated. A few studies are available on the dermatologic diseases in this population. Hence, this study is undertaken to evaluate the spectrum of skin changes in the elderly population.

Materials and Methods: This study was conducted in the Department of Dermatology, Sri Devaraj Urs Medical College, attached to RL Jalappa Hospital, Kolar, Karnataka, India. A total of 300 patients were recruited for this study, among them 185 (61.6\%) were males and $115(38.4 \%)$ were females. All the patients aged more than 60 years with skin disorders attending the dermatology OPD were included in the study. A detailed physical and clinical examination was performed for all the study subjects. Patients with genodermatoses, albinism, premature aging and inherited disorders of DNA which may interfere with chronological aging skin were excluded from the study.

Results: Out of 300 patients, 185 cases $(61.6 \%)$ were males and 115 cases $(38.4 \%)$ were females. Pruritus was the commonest complaint in 186 patients $(62 \%)$. Among the chronological changes of aged skin, wrinkling was the commonest manifestation observed in $282(94 \%)$ cases. The most commonly observed diseases were eczematous dermatitis in 133 (44.3\%) cases, followed by infections and infestations in 122 $(40.6 \%)$ and papulo-squamous diseases in $33(11 \%)$. A total of $46(15.3 \%)$ patients were found to have papulo-squamous disorders. Psoriasis vulgaris was observed in 21 (7\%) cases. Among premalignant and malignant disorders, $4(1.3 \%)$ cases had actinic chelitis, $2(0.6 \%)$ cases of basal cell carcinoma and $1(0.3 \%)$ case of squamous cell carcinoma. A total of 5 patients had connective tissue disorders. The comorbid conditions included hypertension in $49(16.3 \%)$ cases, followed by diabetes mellitus in $31(10.3 \%)$ and 5 (1.6\%) patients had hypothyroidism.

Conclusion: Dermatological findings in geriatric population are universal and cause considerable morbidity. This would necessitate the need for conducting an exclusive evaluation for these patients.
\end{abstract}

C 2020 Published by Innovative Publication. This is an open access article under the CC BY-NC-ND license (https://creativecommons.org/licenses/by/4.0/)

\section{Introduction}

Dermatological problems in the elderly are common and the prevalence will continue to increase because of elevated levels of life expectancy. The burden of the dermatological disease in older population is significant and often underestimated. ${ }^{1}$ Aging of the skin, chronic diseases, personal skin care habits and poly-pharmacy predisposes the geriatric population for various skin disorders. ${ }^{2,3}$

\footnotetext{
* Corresponding author.

E-mail address: drrajeshg@gmail.com (Rajesh G).
}

In India, there are about 104 million elderly individuals out of which 53 million are females and 51 million males according to 2011 population census and this may increase dramatically over the next four decades. ${ }^{4}$ The Indian population aged more than 60 and above is projected to increase from $8 \%$ in 2010 to $19 \%$ in 2050, according to the United Nations Population Division (UN $2011)^{5,6}$ In India the geriatric population was $6.9 \%$ of total population in 2011 and may increase to $12.4 \%$ by $2026 .^{7}$ The most common manifestations of the skin diseases in geriatric population are xerosis, asteatotic dermatitis, 
degenerative changes like wrinkles, infectious diseases including bacterial, viral and fungal infections, infestation, eczema, neoplasms, papulo-squamous disorders, psoriasis, non-healing ulcers, hair and nail changes, immune-bullous disorders like bullous pemphigoid. ${ }^{7,8}$

A few epidemiological studies reported that in the elderly population skin diseases have high prevalence. For example, the prevalence of xerosis cutis range up to $85.5 \%$, benign skin tumours up to $74.5 \%$, fungal infections up to $77 \%$ and pressure ulcer (PU) up to $46 \% . .^{2}$ Geriatric patients with skin diseases have an increased risk for mental and behavioural disorders, especially depression. ${ }^{2,9}$

Aging is a complex, natural process which is progressive reduction in maximal functioning and reverse capacity of all organs including skin, time dependent deterioration due to accumulation of molecular damage. The skin is a complex and dynamic organ that shows the most obvious signs of aging. Skin, the largest and most visible organ of the body bears the brunt of being the beacon of ageing. ${ }^{7,10}$

Aging of the skin can classified as intrinsic and extrinsic aging categories. Intrinsic or chronologic aging refers to changes on sun-protected skin and the extrinsic aging, refer to changes on sun-exposed skin. Two major theories of aging exist. The genetic program theory describes it as an irreversible, orderly process, whereas the stochastic theory implicates "wear and tear" by random environmental assaults. ${ }^{7,11}$ In addition to this, poor immune response in geriatric population predisposes them to skin diseases. Also, the incidence of cutaneous neoplasms increases due to lack of immune response. Wound healing process is impaired because of reduced inflammatory and immune response, delayed replenishment of blood vessels and diminished collagen degradation. ${ }^{10}$ In India, very few studies have been conducted on geriatric dermatoses. Hence, this study is undertaken to evaluate the spectrum of skin changes in the elderly population of a tertiary care hospital.

\section{Materials and Methods}

This study was conducted in the Department of Dermatology, Venereology, and Leprosy, Sri Devaraj Urs Medical College, attached to RL Jalappa Hospital, a constituent of Sri Devaraj Urs Academy of Higher Education and Research (SDUAHER), Kolar, Karnataka, India. A total of 300 patients were recruited for this study, among them $185(61.6 \%)$ were males and $115(38.4 \%)$ were females. All patients aged more than 60 years with skin disorders attending dermatology OPD were included in this study. A detailed physical and clinical examination was done for all the study subjects. The following parameters were recorded such as age, sex, age of onset, duration, site, size and number of lesions, and morphology. Those cases with doubtful diagnosis were subjected to investigations like gram stain, tzanck smear, $\mathrm{KOH}$ mount, and skin biopsy for histo-pathological examination if necessary. If underlying systemic disease was found relevant investigations were done (CBC, Urine routine, ESR, LFT, RFT, lipid profile, thyroid function test). Prevalence of the dermatoses in elderly and relationship if any with occurrence of dermatoses and the underlying systemic condition were studied. Patients with genodermatoses, albinism, premature aging and inherited disorders of DNA which may interfere with changes of aging skin were excluded from the study.

\section{Results}

Out of 300 patients, 185 cases (61.6\%) were males and 115 cases $(38.4 \%)$ were females. Maximum number of patients were from rural areas (68.6\%) 206 cases. Majority being farmers $96(51.8 \%)$, and housewives $74(64.3 \%)$. Pruritus was the commonest complaint in 186 patients $(62 \%)$. Most of the patients belonged to 60-70 years age group (182) comprising $60.6 \%$ as shown in Table 1.

Table 1: Age wise distribution of the patients

\begin{tabular}{lcc}
\hline Age (in years) & No. of Cases & Percentage \\
$60-70$ & 182 & $60.6 \%$ \\
$71-80$ & 73 & $24.3 \%$ \\
$81-90$ & 34 & $11.3 \%$ \\
$91-100$ & 11 & $3.6 \%$ \\
\hline
\end{tabular}

Among the physiological changes of aging skin wrinkling was the commonest manifestation observed in $282(94 \%)$ cases followed by seborrheic keratosis in 230 $(76,6 \%)$ cases and xerosis in $185(61.6 \%)$ cases as illustrated in Table 2.

Table 2: Physiological changes of aging in geriatric patients

\begin{tabular}{lcc}
\hline Physiological changes & $\begin{array}{c}\text { No. of } \\
\text { Cases }\end{array}$ & Percentage \\
Wrinkling & 282 & $94.0 \%$ \\
Seborrheic keratoses & 230 & $76.6 \%$ \\
Xerosis & 185 & $61.6 \%$ \\
Cherry angiomas & 178 & $59.3 \%$ \\
Idiopathic guttate hypomelanosis & 132 & $44.0 \%$ \\
Senile comedones & 49 & $16.3 \%$ \\
\hline
\end{tabular}

The most commonly observed diseases were eczematous dermatitis in $133(44.3 \%$ ) cases, followed by infections and infestations in 122(40.6\%) and papulo-squamous diseases in $33(11 \%)$. The most frequent types of eczematous dermatitis were asteatotic eczema in $34(11.3 \%)$ cases, discoid eczema in 22(7.3\%) cases, hand eczema in 13(4.3\%) cases, prurigo nodularis in $11(3.6 \%)$ cases and lichen simplex chronicus in $8(2.6 \%)$ cases as shown inTable 3.

The commonly noticed fungal infections were tinea corpris in $28(9.3 \%)$ cases, tinea unguium in $10(3.3 \%)$ cases, tinea pedis in $7(2.3 \%)$ cases and candidiasis in $5(1.6 \%)$ cases. The frequently seen bacterial infections were pyodermas in $32(10.6 \%)$ cases. The most frequent viral 
Table 3: Prevalence of Eczematous dermatitis in geriatric patients

\begin{tabular}{lcc}
\hline Disorders & No. of Cases & Percentage \\
Eczemas & 34 & $11.3 \%$ \\
Asteatotic eczema & 22 & $7.3 \%$ \\
Discoid eczema & 13 & $4.3 \%$ \\
Hand eczema & 11 & $3.6 \%$ \\
Prurigo nodularis & 8 & $2.6 \%$ \\
Lichen simplex chronicus & & \\
\hline
\end{tabular}

infections were herpes zoster in $12(4 \%)$ cases and warts in $9(3 \%)$ cases and $6(2 \%)$ patients had scabies as shown in Table 4.

Table 4: Prevalence of Infections and infestations in geriatric patients

\begin{tabular}{lcc}
\hline Disorders & $\begin{array}{c}\text { No. of } \\
\text { Cases }\end{array}$ & Percentage \\
Infections and infestations & 45 & $15 \%$ \\
Dermatophytosis & 32 & $10.6 \%$ \\
Pyoderma & 12 & $4 \%$ \\
Herpes zoster & 9 & $3 \%$ \\
Warts & 6 & $2 \%$ \\
Scabies & 6 \\
\hline
\end{tabular}

A total of $46(15.3 \%)$ patients were found to have papulosquamous disorders in our study. Psoriasis vulgaris was observed in $21(7 \%)$ cases, lichen planus in $10(3.3 \%)$ cases and cutaneous lichen sclerosus et atrophicus in $4(1.3 \%)$ cases. In this study, immuno-bullous disorders was observed in $8(2.6 \%)$ cases. There were $4(1.3 \%)$ cases of bullous pemphigoid followed by $2(0.6 \%)$ cases of pemphigus vulgaris, 1 case of dermatitis herpetiformis and Linear IgA disease each as depicted inTable 5.

Table 5: Prevalence of Papulo-squamous and Immuno-bullous disorders in geriatric patients

\begin{tabular}{lcc}
\hline $\begin{array}{l}\text { Disorders } \\
\text { Papulo-squamous disorders }\end{array}$ & $\begin{array}{c}\text { No. of } \\
\text { Cases }\end{array}$ & Percentage \\
$\begin{array}{l}\text { Psoriasis vulgaris } \\
\text { Lichen planus }\end{array} \quad \begin{array}{cc}\text { Immuno-bullous disorders } \\
\text { Bullous pemphigoid }\end{array}$ & $7 \%$ \\
Pemphigus vulgaris & 21 & $3.3 \%$ \\
Dermatitis herpetiformis & 1 & $1.3 \%$ \\
Linear IgA disease & 1 & $0.6 \%$ \\
\end{tabular}

Among premalignant and malignant disorders, 4 (1.3\%) cases had actinic chelitis, $2(0.6 \%)$ cases of basal cell carcinoma and $1(0.3 \%)$ case of squamous cell carcinoma. A total of 6 patients had adverse drug reactions, $3(1 \%)$ cases of fixed drug eruptions, $2(0.6 \%)$ cases of drug induced macular rash and a case $(0.3 \%)$ of steven-johnson syndrome. A total of 5 patients had connective tissue disorders comprising $3(1 \%)$ cases of discoid lupus erythematosus, and one case $(0.3 \%)$ of morphea and systemic sclerosis each. Among the other disease conditions, there were 10
$(3.3 \%)$ cases of post herpetic neuralgia, 8 (2.6\%) patients had vitiligo, $9(3 \%)$ patients had alopecia areata, $6(2 \%)$ patients had urticaria, $4(1.3 \%)$ patients had keloid, 2 $(0.6 \%)$ patients had leucocytoclastic vasculitis, $2(0.6 \%)$ patients were found to have Sweet's syndrome and a case of granuloma annulare as mentioned in table 6 . In addition to this, associated systemic illnesses observed in 96 (32\%) patients. Hypertension in $49(16.3 \%)$ cases, followed by diabetes mellitus in $31(10.3 \%)$ were the most common diseases and $5(1.6 \%)$ patients had hypothyroidism.

Table 6: Prevalence of Connective tissue disorders, Premalignant and Malignant disorders, adverse drug reactions and other disease condition in geriatric patients

\begin{tabular}{|c|c|c|}
\hline $\begin{array}{l}\text { Disorders } \\
\text { Connective tissue disorders }\end{array}$ & $\begin{array}{l}\text { No. of } \\
\text { Cases }\end{array}$ & Percentage \\
\hline Discoid lupus erythematosus & 3 & $1 \%$ \\
\hline Morphea & 1 & $0.3 \%$ \\
\hline Systemic sclerosis & 1 & $0.3 \%$ \\
\hline \multicolumn{3}{|c|}{ Premalignant and Malignant disorders } \\
\hline Actinic keratoses & 4 & $1.3 \%$ \\
\hline Basal cell carcinoma & 2 & $0.6 \%$ \\
\hline Squamous cell carcinoma & 1 & $0.3 \%$ \\
\hline \multicolumn{3}{|c|}{ Adverse drug reactions } \\
\hline Fixed drug eruptions & 3 & $1 \%$ \\
\hline Drug rash (macular) & 2 & $0.6 \%$ \\
\hline Steven Johnson's syndrome & 1 & $0.3 \%$ \\
\hline \multicolumn{3}{|c|}{ Others } \\
\hline Post herpetic neuralgia & 10 & $3.3 \%$ \\
\hline vitiligo & 8 & $2.6 \%$ \\
\hline Alopecia areata & 9 & $3 \%$ \\
\hline urticaria & 6 & $2 \%$ \\
\hline keloid & 4 & $1.3 \%$ \\
\hline Sweet's syndrome & 2 & $0.6 \%$ \\
\hline Leucocytoclastic vasculitis & 2 & $0.6 \%$ \\
\hline Granuloma annulare & 1 & $0.3 \%$ \\
\hline \multicolumn{3}{|l|}{ Systemic diseases } \\
\hline Hypertension & 49 & $16.3 \%$ \\
\hline Diabetes mellitus & 31 & $10.3 \%$ \\
\hline hypothyroidism & 5 & $1.6 \%$ \\
\hline
\end{tabular}

\section{Discussion}

In the present study, all subjects aged above 60 years were appraised. Geriatric population constitutes a large and rapidly growing segment of Indian population. Skin diseases in elderly are increasing and thus can exert a great burden on health care system. It is important to identify the patterns of geriatric skin disorders for effective delivery of health care services. ${ }^{12}$

In our study, various physiological signs of aging were studied, which is an inescapable process. The skin findings were suggestive of changes that were result of cumulative sun exposure during the entire lifespan. These changes of photo aging were superimposed with intrinsic aging. Although most of the changes studied were harmless to 
elderly, few had an adverse impact like chronic actinic dermatitis and cutaneous malignancy. The age group of patients with a majority of cutaneous manifestations in our study was comparable to the study conducted by Agarwal R et al. ${ }^{13}$

In our study, wrinkling was observed in 282 (94\%) cases. Grover $\mathrm{S}$ and Narasimhalu ${ }^{14}$ and Durai, Thappa et al ${ }^{15}$ have reported wrinkling in $95.5 \%$, and $99 \%$ patients respectively which agrees with the results of our study. Most of the wrinkling seen in this study was on sun exposed areas like the face, neck, forearms and dorsa of hands in the form of glyphic wrinkles. A slightly lower incidence of wrinkling in our study could be because of increased tolerance of racially pigmented skin to sunlight.

In the present study, seborrheic keratoses was noted in $230(76.6 \%)$ cases and xerosis was observed in 185 (61.6\%) cases. In a study conducted by Leena Raveendra, xerosis was observed in $93 \%$ of patients. ${ }^{15,16}$ Durai PC, et al. reported xerosis in $99.8 \%$ of patients. The high prevalence of xerosis in the present study was similar to study by Raghavendra $\mathrm{L}^{16}$ and Durai PC. ${ }^{15}$

Preeja $\mathrm{R}$ et al., reported the following findings viz., xerosis $(54.9 \%)$, cherry angioma $(17.1 \%)$, acrochordon (24.4\%), seborrhoeic keratoses (17.8\%), senile comedones $(9.1 \%)$ in their study. Among the eczemas, asteatotic eczema was most commonly (5.8\%) noted. ${ }^{8}$

In our study, pruritus was the commonest complaint in 186 patients $(62 \%)$. Most of the patients belonged to $60-70$ years age group (182) comprising $60.6 \%$. Pruritus is a very common dermatological complaint of the elderly population and the causes can be varied. Patange and Fernandez noted pruritus in $78.5 \%$ of their patients which was higher than the what was observed in this study. ${ }^{17}$

In our study eczematous disorders was observed in 88 (29.3\%) patients. The total incidence of eczemas in various studies ranges from $11.9 \%$ to $58 \% \% .^{18-20}$ The incidence of stasis dermatitis in the study is in concordance with the study by Beauregard and Gilchrest, Souissi A et al., and Liao YH et al,

Commonly observed dermatophytosis in our study were tinea corporis in 28 (9.3\%) cases, tinea unguium in 10 $(3.3 \%)$ cases, tinea pedis in $7(2.3 \%)$ cases and candidiasis in $5(1.6 \%)$ cases. The frequently seen bacterial infections were pyodermas in $32(10.6 \%)$ cases. The most frequent viral infections were herpes zoster in $12(4 \%)$ cases and warts in $9(3 \%)$ cases and $6(2 \%)$ patients had scabies. The above findings were similar to study conducted by by Preeja $\mathrm{R}$ et al. ${ }^{8}$

A total of $46(15.3 \%)$ patients were found to have papulosquamous disorders in our study. Psoriasis vulgaris was observed in $21(7 \%)$ cases, lichen planus in $10(3.3 \%)$ cases and cutaneous lichen sclerosus et atrophicus in $4(1.3 \%)$ cases. Immuno-bullous disorders were observed in $8(2.6 \%)$ cases. There were $4(1.3 \%)$ cases of bullous pemphigoid followed by $2(0.6 \%)$ cases of pemphigus vulgaris, One case each of dermatitis herpetiformis and Linear IgA dermatoses was disease was also noted.

In a study by M. Vairaprabha Devi and N C. Manikandan, the authors reported papulosquamous disorders in $4.5 \%$ of the study population. Among them psoriasis was the commonest disorder noted (3\%). Thapa DP et al., ${ }^{21}$ reported that the incidence of papulosquamous disorders in geriatric population was $3.3 \%$ and Raveendra $\mathrm{L}$, reported that the bullous disorders and eczema were seen in $1.5 \%$ and $31 \%$ respectively. ${ }^{16}$

In this study, Discoid lupus erythematosus wes observed in $3(1 \%)$, which is comparable with the studies done by Chopra A $2.3 \%$ and Najdawi F $(0.43 \%) .{ }^{22,23}$ We observed vitiligo in $8(2.6 \%)$ cases .Raveendra L, reported vitiligo in $16(8 \%)$ cases. $^{16}$ IIn this study, systemic diseases were observed in 96 (32\%) patients. Hypertension was the commonest disease and observed in $49(16.3 \%)$ cases. Radhakrishnan et al., reported incidence of hypertension in $59 \%$ of cases. ${ }^{24}$ IIn our study, diabetes was noted in $31(10.3 \%)$ which is quite lower than other studies by Radhakrishnan 36\%. ${ }^{24}$ and Sahoo. ${ }^{25}$ We reported 5 (1.6\%) patients having hypothyroidism. It may be due to difference in lifestyle of population.

\section{Conclusion}

Dermatological diseases in geriatric population cause considerable morbidity, especially if associated with other comorbid conditions, so health promotion and education can do much to reduce the risk. Large epidemiological studies in different regions of the country are recommended.

\section{Conflict of interest}

None.

\section{Source of funding}

None.

\section{References}

1. Padma D, Sudhavani M, Shahana N, Bhavana GN, Netha. Prevalence of Geriatric Dermatosis - A Study. Int Arch Integrated Med. 2018;5(10):121-126

2. Hahnel E, Blume-Peytavi U, Trojahn C, Dobos G, Jahnke I, et al. Prevalence and associated factors of skin diseases in aged nursing home residents: a multicentre prevalence study. BMJ Open. 2017;7:e018283.

3. Jafferany M, Huynh TV, Silverman MA, Zaidi Z. Geriatric dermatoses: a clinical review of skin diseases in an aging population. Int J Dermatol. 2012;51:509-522.

4. Nirupama, Tatavarthi, Bhagyalakshmi. Clinico Epidemiological Study of Geriatric Dermatoses. Indian J Appl Res. 2019;9(6):69-70.

5. Ghosh A, Jahan F, Choubey P. Shyam Sundar Chaudhary. Spectrum of Geriatric Dermatoses in Jharkhand. IOSR J Dent Med Sci (IOSRJDMS). 2017;16(7):59-62.

6. 6.United Nations Population Division (UN), World Population Prospects: The 2010 Revision (New York: United Nations, 
2011);Available from: accessedathttp://esa.un.org/unpd/wpp/1ndex. htm.

7. Agarwal S, Verma A, Bagri M, Bishnoi S, Rathod N, Nijhawan M. Geriatric Dermatosis in Western Rajasthan. IOSR J Dent Med Sci (IOSR-JDMS). 2019;18(7):44-47.

8. R P, Ashok P, Samson JF. A clinical study of geriatric dermatoses. $J$ Evol Med Dent Sci. 2017;6(59):4338-4342.

9. Kim EK, Kim HO, Park YM, Park CJ, Yu DS, et al. Prevalence and risk factors of depression in geriatric patients with dermatological diseases. Ann Dermatol. 2013;25:278-284.

10. Devi MV, Manikandan NC. Clinical study of geriatric dermatoses. Int J Res Dermatol. 2019;5(1):128-133.

11. Yaar M, Gilchrest BA. Cellular and Molecular Mechanisms of Cutaneous Aging. J Dermatol Surg Oncol. 1990;16:915.

12. Jindal R. Skin Disorders Among Geriatric Population at a Tertiary Care Center in Uttarakhand. J Clin Diagn Res. 2016;10(3):WC6WC08.

13. Agarwal R, Sharma L, Chopra A, Mitra D, Saraswat N. A crosssectional observational study of geriatric dermatoses in a Tertiary Care Hospital of Northern India. Indian Dermatol Online J. 2019;10:524524.

14. Grover S, Narasimhalu CRV. A clinical study of skin changes in geriatric population. Indian J Dermatol, Venereol Leprol. 2009;75(3):305-306.

15. Thappa DM, Durai P, Kumari R, Malathi $M$. Aging in elderly: Chronological versus photoaging. Indian J Dermatol. 2012;57(5):343-352

16. Raveendra L. A clinical study of geriatric dermatoses. Our Dermatol Online. 2014;5(3):235-239.

17. Patange VS, Fernandez RJ. A study of geriatric dermatoses. Ind J Dermatol Venerol Leprol. 1995;61:206-208.

18. Beauregard S, Gilchrest BA. A survey of skin problems and skin care regimens in the elderly. Arch Dermatol. 1987;123:1638-1643.
19. Souissi A, Zeglaoui F, N EF, Fazaa B, Zouari B, Kamoun MR. Skin diseases in elderly: A multicentre Tunisian study. Ann Dermatol Venerol. 2006;133:231-234.

20. Liao YH, Chen KH, Tseng MP, Sun CC. Pattern of skin diseases in a geriatric patient group in Taiwan. A 7 year survey from the outpatient clinic of a university medical center. Dermatology. 2001;203:308313.

21. Thapa DP, Jha AK, Kharel C, Shreshta S. Dermatological problems in geriatric patients: a hospital based study. Nepal Med Coll J. 2012;14:193-195.

22. Chopra A. Skin diseases in the elderly. Indian J Dermatol, Venereol Leprol. 1999;65(5):245-246.

23. Najdawi F, Faaposouri M. Frequency and types of skin disorders and associated diabetes mellitus in elderly Jordanians. Eastern Mediterr Health J. 2002;8(4-5):574-578.

24. Radhakrishnan S, Balamurugan S. Prevalence of diabetes and hypertension among geriatric population in a rural community of Tamilnadu. Indian J Med Sci. 2013;67:130-136.

25. Sahoo A, Singh PC, Pattnaik P, Panigrahi RK. Geriatric dermatoses in southern Orissa. Indian J Dematol. 2000;45:66-68.

\section{Author biography}

\section{Raghavendra B N Professor}

Rajesh G Associate Professor

Cite this article: Raghavendra B N , Rajesh G . A study of geriatric dermatoses in a rural based tertiary care hospital in South India. IP Indian J Clin Exp Dermatol 2020;6(1):62-66. 